\title{
Yes, circadian rhythms actually do affect almost everything
}

\author{
Cell Research (2016) 26:759-760. doi:10.1038/cr.2016.65; published online 31 May 2016
}

Circadian rhythms in the level of intracellular $\mathrm{Mg}^{2+}$ appear to be widely conserved phylogenetically, and have the potential to impact nearly all aspects of metabolism. Moreover, the clock regulates the ion channels that generate the rhythm, demonstrating that the whole cell operates as a circadian system.

Recent work from Feeney et al. [1] has demonstrated rhythms in the level of intracellular magnesium $\left(\left[\mathrm{Mg}^{2+}\right]_{\mathrm{i}}\right)$, the essential cofactor of ATP and other nucleotide triphosphates. Mg-NTP levels can influence myriad aspects of cellular metabolism and the $\left[\mathrm{Mg}^{2+}\right]_{\mathrm{i}}$ rhythms appear to be conserved among widely dispersed systems representing the eukaryotes. Hence the title: Circadian rhythms (in $\left[\mathrm{Mg}^{2+}\right]_{\mathrm{i}}$ ) actually do have the potential to affect almost everything.

Circadian rhythms exist because the living things that have them - and nearly all eukaryotes do display such rhythms - find them to be adaptive [2]. Rhythms allow the cell to anticipate regular changes so that appropriate cellular activities happen at appropriate times of day; cells whose internal rhythms are out of sync with their environment do not grow as well as cells whose clocks are in tune [3, 4]. For several decades the rhythm field has been focusing on dissection of the core oscillator(s) driving these rhythms; this is a problem now reaching end game with generally accepted models for the three distinct but conserved mechanisms found in cyanobacteria, in plants, and in fungi/animals [5]. However, what this paragraph's opening sentence really means is that selection has been driven by the adaptive significance of circadian output control, and for this the nature of the oscillator itself matters much less than the pathways of control. Herein lies the compelling interest in the emerging theme of circadian control of metabolism.

Even a decade ago circadian regulation of output was viewed as a passive and unidirectional flow of control: light and temperature set the phase of the oscillator; the oscillator drove output (chiefly through transcriptional control of clock-controlled genes, so called $c c g$ s [6]); $c c g$ transcripts were translated to yield a rhythmic proteome; the proteins produced a metabolome. As we (as a field) dig more deeply into these steps, it is more and more apparent that each step confers its own brand of regulation, but the aspect discovered by Feeney et al. [1] is particularly pervasive and therefore demands attention.

The nuts and bolts: What did they do? The authors used inductively coupled plasma mass spectrometry, supplemented by a luciferase-based $\mathrm{Mg}^{2+}$ assay, to track ionic content of a variety of cells in culture (the micro-alga Ostreococcus tauri, Neurospora crassa, human osteosarcoma U2OS cells, and lung fibroblasts), revealing rhythms in intracellular levels of several ions $\left(\mathrm{K}^{+}\right.$, $\left.\mathrm{Mg}^{2+}, \mathrm{Li}^{+}, \mathrm{Na}^{+}, \mathrm{Fe}^{2+}, \mathrm{Co}^{+}, \mathrm{Zn}^{2+}, \mathrm{Se}^{+}\right)$. Of these $\mathrm{Mg}^{2+}$ was of note because it is the essential cofactor for all NTP-driven processes. Although seemingly widely conserved, the observed rhythms are not of notable amplitude, typically ranging from 1.3 to 2 fold, and the phasing is different in different cell types (dusk in Ostreococcus, morning in Neurospora, late day in U2OS cells). Controls show that these are genuine cell-autonomous, temperature-compensated and -entrainable circadian rhythms, and not merely an epi-phenomenon. Intriguingly, the rhythms arise because all (or nearly all) genes encoding $\mathrm{Mg}^{2+}$ transporters, channels, and exchangers are $c c g$ s in several different systems.

Now we will accept that the observation of a 1.5 -fold rhythm in $\left[\mathrm{Mg}^{2+}\right]_{\mathrm{i}}$ in-and-of itself might elicit a yawn, but this is where the story gets fascinating: $\left[\mathrm{Mg}^{2+}\right]_{\mathrm{i}}$ influences both the clock and clock output, including therefore its own rhythm as conferred by the $c c g$ ion channels; i.e., the circadian system subsumes the whole cell. Several lines of evidence reveal this. siRNA knockdown or chemically-mediated transporter inhibition increases $\left[\mathrm{Mg}^{2+}\right]_{\mathrm{i}}$ to an extent influenced by extracellular $\mathrm{Mg}^{2+}$, and such changes in $\left[\mathrm{Mg}^{2+}\right]_{\mathrm{i}}$ are well correlated in a dosedependent manner with biologically significant period lengthening (4-6 h, not a tiny effect). Indeed, simply changing extracellular $\left[\mathrm{Mg}^{2+}\right]$ can influence or abolish the rhythm and abrupt changes in $\left[\mathrm{Mg}^{2+}\right]_{\mathrm{i}}$ can completely reset the rhythm and dictate phase.

Second, the $\left[\mathrm{Mg}^{2+}\right]_{\mathrm{i}}$ rhythm influences circadian output globally. Energy in cells is typically equated to energy charge, but ATP must be bound to $\mathrm{Mg}^{2+}$ for it to be biologically active; thus a rhythm in $\left[\mathrm{Mg}^{2+}\right]_{\mathrm{i}}$ means a rhythm in effective energy charge. Moreover, translation is a very energy-intensive process, and overall rates of translation as assayed by puromycin incorporation are rhythmic in both U2OS cells [7] and Ostreococcus, with a peak time correlated with the peak of $\left[\mathrm{Mg}^{2+}\right]_{\mathrm{i}}$. mTOR1 mediates rhythms in translation in U2OS cells [7] and is highly respon- 
sive to Mg-ATP levels. In an important experiment, the authors showed that inhibitors of mTOR abolished the ability of low extracellular $\left[\mathrm{Mg}^{2+}\right]$ to lengthen period. This experiment transcends the simple correlation between changes in $\left[\mathrm{Mg}^{2+}\right]_{\mathrm{i}}$ and clock parameters by demonstrating that changes in $\left[\mathrm{Mg}^{2+}\right]_{\mathrm{i}}$ act through mTOR to influence translation.

Finishing out the significance of the $\left[\mathrm{Mg}^{2+}\right]_{\mathrm{i}}$ rhythms is the realization that there must be a host of undescribed consequences. Mg-ATP is used in $>600$ cellular reactions/enzymes [8], and there are in addition all the reactions using other NTPs - replication, transcription, translation, signaling, motility - it is a grab bag of cell biology. Indeed, circadian rhythms actually do have the potential to affect almost everything.

Although not mentioned explicitly, a potentially interesting corollary of the apparent rhythm in Mg-ATP is the impact that could be expected to have on ubiquitously used, and Mg-ATP-dependent, firefly luciferase reporters. As long as (1) luciferin is not rate-limiting (which should never be the case for the reporter to be useful), and (2) the $\mathrm{Km}$ of luciferase for Mg-ATP is not so low compared to $\left[\mathrm{Mg}^{2+}\right]_{\mathrm{i}}$ that luciferase is always saturated anyway, it is plain that a constitutively expressed gene or protein could appear to be rhythmically present when its expression is tracked through the use of such a reporter. Aside from these caveats, there seems no resolution to this dilemma aside from knowledge of phase: The waveform of all luciferase reporter rhythms must be influenced to some extent by the $\left[\mathrm{Mg}^{2+}\right]_{\mathrm{i}}$ rhythm, but this influence must track the $\left[\mathrm{Mg}^{2+}\right]_{\mathrm{i}}$ rhythm, thus if the reporter peaks at a time different from the peaks in $\left[\mathrm{Mg}^{2+}\right]_{\mathrm{i}}$, one can at least be assured that the observed rhythm is not solely driven by the $\left[\mathrm{Mg}^{2+}\right]_{\mathrm{i}}$ rhythm.

The overall concept here is that the circadian system regulates channels and transporters that traffic in $\mathrm{Mg}^{2+}$ resulting in rhythms in $\left[\mathrm{Mg}^{2+}\right]_{i}$ with peaks at times of high energy demand; these may be phased differently in different cell types. Necessarily, the $\left[\mathrm{Mg}^{2+}\right]_{\mathrm{i}}$ rhythm impacts circadian output through the immediate effects on energy charge and translation as well as through the requirement of so many cellular processes for Mg-NTP. The $\left[\mathrm{Mg}^{2+}\right]_{\mathrm{i}}$ rhythm affects the oscillator by virtue of its global effect on translation. This makes sense, the observation that inhibition of translation can reset the clock or lengthen period being an ancient truth that even predates the molecular era [9-11].

Jay C Dunlap ${ }^{1}$, Jennifer J Loros ${ }^{1,2}$

${ }^{1}$ Department of Molecular and Systems Biology, ${ }^{2}$ Department of Biochemistry, Geisel School of Medicine at Dartmouth, Hanover, NH 03755, USA Correspondence: Jay C Dunlap ${ }^{\mathrm{a}}$, Jennifer J Loros ${ }^{\mathrm{b}}$

aE-mail: jay.c.dunlap@dartmouth.edu

bE-mail: Jennifer.loros@dartmouth.edu

\section{References}

1 Feeney KA, Hansen LL, Putker M, et al. Nature 2016; 532:375-379.

2 Yerushalmi S, Green RM. Ecol Lett 2009; 12:970-981.

3 Ouyang Y, Andersson CR, Kondo T, et al. Proc Natl Acad Sci USA 1998; 95:86608664.

4 Wang GZ, Hickey SL, Shi L, et al. Cell Rep 2015; 13:1868-1880.

5 Dunlap JC, Loros JJ, Decoursey P, eds. Molecular Biology of Circadian Pacemaker Systems, in Chronobiology: Biological Timekeeping. Sunderland, MA: Sinauer Assoc., 2004; 210-251.

6 Loros JJ, Denome SA, Dunlap JC. Science 1989; 243:385-388.

7 Lipton JO, Yuan ED, Boyle LM, et al. Cell 2015; 161:1138-1151.

8 de Baaij JH, Hoenderop JG, Bindels RJ. Physiol Rev 2015; 95:1-46.

9 Feldman JF. Proc Natl Acad Sci USA 1967; 57:1080-1087.

10 Rothman BS, Strumwasser F. J Gen Physiol 1976; 68:359-384.

11 Taylor WR, Dunlap JC, Hastings JW. J Exp Biol 1982; 97:121-136. 